
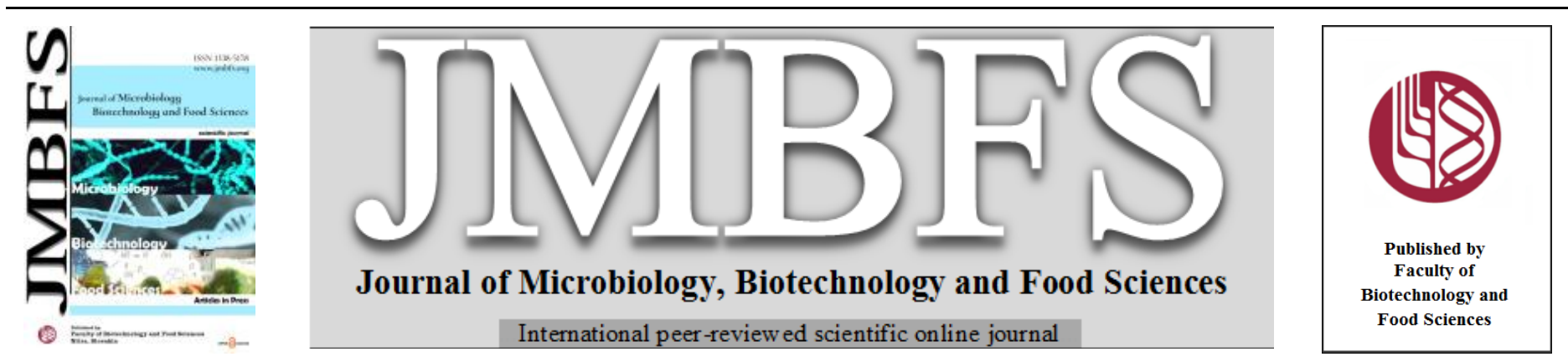

\title{
ANTIMICROBIAL CHARACTERISTICS OF BIOACTIVE COMPOUNDS BY A THERMOTOLERANT MICROALGA CHLORELLA VULGARIS ISOLATED FROM THERMAL SPRINGS OF TURKEY
}

\author{
Nur Koçberber Kılıç ${ }^{1 *}$ Elif Safran ${ }^{1}$, Gönül Dönmez ${ }^{1}$ \\ Address(es): Nur Koçberber Kılıç \\ ${ }^{1}$ Department of Biology, Faculty of Science; Ankara University, 06100, Ankara, TURKEY, +90312 2126720.
}

*Corresponding author: nrkilic@ankara.edu.tr

https://doi.org/10.55251/jmbfs.2285

\section{ARTICLE INFO}

Received 31. 10. 2019

Revised 21. 1. 2022

Accepted 24. 1. 2022

Published 1. 6. 2022

Regular article

open $\partial_{\text {Access }}$

\section{ABSTRACT}

This study presents bioactive character of 10 thermal microalgae that were isolated from thermal springs (Turkey). Strain A was the most successful microorganism with the maximum antimicrobial activity. Strain A was identified as C. vulgaris according to its 18S rDNA. The effect of nitrogen concentrations $(0.5 \mathrm{~g} / \mathrm{L}, 1.0 \mathrm{~g} / \mathrm{L}$, and $1.5 \mathrm{~g} / \mathrm{L})$ and temperatures $\left(30^{\circ} \mathrm{C}\right.$ and $\left.45^{\circ} \mathrm{C}\right)$ on bioactive compounds production by thermotolerant $C$. vulgaris was studied. The highest antimicrobial effect was found in the biomass when microalga was cultivated in media with $1.0 \mathrm{~g} / \mathrm{L}$ nitrogen at $30^{\circ} \mathrm{C}$. On the other hand, stress conditions like $45^{\circ} \mathrm{C}$ and media with $1.5 \mathrm{~g} / \mathrm{L}$ nitrogen, microalgae produced more efficient bioactive compounds then at $30^{\circ} \mathrm{C}$ in media with $1.5 \mathrm{~g} / \mathrm{L}$ nitrogen. $S$. aureus ATCC BAA 976 and $S$. aureus ATCC 1026 were affected the most by bioactive compounds of $C$. vulgaris. In addition, chloroform was the most efficient solvent to obtain effective extracts from $C$. vulgaris. Pigments and polar compounds had important role for higher antimicrobial activity under harsh conditions like $45^{\circ} \mathrm{C}$ and media with $1.5 \mathrm{~g} / \mathrm{L}$ nitrogen. In addition, caffeic acid having bioactive character was firstly shown for $C$. vulgaris in the current study.

Keywords: bioactive compounds, antimicrobial activity, Chlorella vulgaris, thermotolerant, stress condition

\section{INTRODUCTION}

Microalgae harvesting energy from sunlight, need only minimal amount of nutrients, fix nitrogen and $\mathrm{CO}_{2}$ and achieve a superior growth rate by utilizing different carbon sources can be found in all around the world. These microorganisms have found usage in areas like human health, industry, and biofuel generation and raised increased interest in recent years. On the other hand, they can produce bioactive compounds having great potential in several biological applications related to human health. It was known that bioactive compounds had several useful properties like antimicrobial, anticancer, antidiabetic, etc. (Gamal, 2010). Such compounds could be chlorophyll, carotene, phenolics, proteins, and fatty acids (Maadane et al., 2017; Rao et al., 2010). Among microalgae, Chlorella genus has been investigated having biological effects in human, animal, and microorganisms (Kitada et al., 2009; Priya, 2012; Plaza et al., 2012; Ibrahim et al., 2015; Syed et al., 2015; Jayshree et al., 2016; Chaidir et al., 2016; Alzahrani et al., 2019). In a previous study performed by Kitada et $\boldsymbol{a l}$. (2009), with different separation methods, extracts of $C$. vulgaris had variable antimicrobial activity against bacteria. Priya (2012) showed that acetone extracts of $C$. vulgaris had antimicrobial activity against Bacillus subtilis, Staphylococcus aureus, Micrococcus luteus, and Klebsiella pneumonia. In another study done with $C$. vulgaris, different methods [pressurized liquid extraction (PLE) and ultrasoundassisted extraction (UAE)] methods were used to obtain microalgal extracts; with PLE extraction and using ethanol, effective bioactive compounds were determined like carotenoids, chlorophylls, sterols, phytols and fatty acids against microorganisms (Plaza et al., 2012). Ibrahim et al. (2015) demonstrated that ethanol extracts of $C$. vulgaris had antimicrobial effect against Gram-positive and Gram-negative bacteria with inhibition zones ranged 6-14 $\mathrm{mm}$. In another study showed that acetone, ethanol, and chloroform extracts of $C$. vulgaris had bioactive character against bacteria related to its phytochemical compounds (Syed $\boldsymbol{e t}$ al., 2015). Jayshree et al. (2016) studied with two microalgae as $C$. vulgaris and Chlamydomonas reinhardtii and they found that methanol extracts of $C$. reinhardtii had better bioactive property than extracts of $C$. vulgaris. Chaidir et al. (2016) performed trials with Chlorella sp. and found that extracts of the microalga had antimicrobial activity to E. coli, Staphylococcus aureus, Salmonella typhii, Bacillus cereus.

The purpose of the study was to find the bioactive compounds produced by a thermotolerant $C$. vulgaris isolated from hot springs. For this, different nitrogen concentrations and temperatures were studied to search the most effective bioactive compound produced by $C$. vulgaris. Different solvent types were also used to find the most effective extract from the tested microalga. Our main aim was to explore the optimum conditions for the most effective bioactive compound by $C$. vulgaris that could be found usage area in biotechnological applications. It is more advantageous to study with a microorganism that can tolerate extreme conditions. Such organisms can produce more stable compounds capable of using biotechnological applications. To our knowledge, there is no report that investigated the thermotolerant $C$. vulgaris with the approach of the current study.

\section{MATERIAL AND METHODS}

Microalgae, conditions of growth

Water samples from thermal springs (Haymana and Kizilcahamam, Turkey) were inoculated on Petri dishes containing BG11 with agar (12 g/l) (Rippka, 1988) (pH 7.5) and incubated at $45^{\circ} \mathrm{C}$ under 2400 lux continuous illumination. Isolated algal cells were purified under aseptic conditions by streaking the cells repeatedly on BG11 agar. These purified microorganisms were inoculated to liquid BG11. These cultures were checked for bacterial contamination. Microalgae were grown in 250 $\mathrm{ml}$ Erlenmeyer with $100 \mathrm{ml}$ of media, at $30^{\circ} \mathrm{C}$ for 14 days under $2400 \mathrm{~lx}$ continuous light intensity at a growth chamber (BINDER, model: KBW 400 (E5.1), S.no: 15-13640, Tuttlingen, Germany).

\section{Selection of microalgae and its identification}

Ten different microalgal strains were inoculated in BG11 and microalga having the most effective bioactive compound was determined. Further experiments were done with it. The selected microalga was identified by its $18 \mathrm{~S}$ rDNA gene. DNA of microalga were amplificated using PCR (2 ml of genomic DNA, $0.4 \mathrm{mM}$ deoxynucleotide triphosphate, 1.25 units of Taq DNA polymerase). Forward primer was F5' CTTGGTCATTTAGAGGAAGTAA and reverse primer was R5 TCCTCCGCTTATTGATATGC. PCR was adjusted to $95^{\circ} \mathrm{C}$ for $5 \mathrm{~min}, 30$ cycles of $95^{\circ} \mathrm{C}$ for $30 \mathrm{sec}, 50^{\circ} \mathrm{C}$ for $30 \mathrm{sec}$, and $72^{\circ} \mathrm{C}$ for $45 \mathrm{sec}$. DNA sequencing analysis was done with Bigdye Cycle kit v3.1 and ABI 3130XL Genetic Analyzer. Phylogenetic analysis of the nearly complete data was performed by BLAST. 
Effect of nitrogen concentration and temperature on bioactive compound production by the selected microalga

Production of bioactive compounds by microalgae was affected from different environmental conditions. Thus, such compounds with different bioactive character could be produced under harsh media. In this context, bioactive compound production by the selected microalga under different media was studied regarding different nitrogen concentrations $(0.5 \mathrm{~g} / \mathrm{L}, 1.0 \mathrm{~g} / \mathrm{L}, 1.5 \mathrm{~g} / \mathrm{L})$, and temperatures $\left(30^{\circ} \mathrm{C}\right.$ and $\left.45^{\circ} \mathrm{C}\right)$. Microalgae were grown in BG11 under $24001 \mathrm{x}$ continuous light intensity at a growth chamber with an incubation period for 14 days.

\section{Effect of different solvent on effectiveness of bioactive compound}

The efficiencies of bioactive compounds prepared by using different solvents can be different. Therefore, ethanol, methanol, hexane, chloroform, Tris-HCI ( $\mathrm{pH}: 8$ $0.5 \mathrm{M}$ ), and water were tested. All the chemicals were purchased from Merck, Germany.

\section{Preparation of bioactive compounds}

After incubation for 14 days, cultures were centrifugated (MPW-351R, Warsaw, Poland) at $10000 \mathrm{rpm}$ for $5 \mathrm{~min}$, supernatant was removed, and biomass was collected. Biomasses were freeze-dried (Millrock Technology, Inc., Kingston, NY 12401, USA) for overnight. Then, dried biomass (1 gram) was exposed to $3 \mathrm{ml}$ ethanol. To obtain algal extract, the mixture was incubated for 1 hour. It was centrifuged for $10000 \mathrm{rpm}(5 \mathrm{~min})$ and supernatant was used as algal extract. Extracts were kept at $4{ }^{\circ} \mathrm{C}$ and analysed within 2 days (Rao et al., 2010; Pradhan et al., 2012).

\section{Determination of bioactive compound effectiveness}

Antimicrobial activity was determined to understand effectiveness of bioactive compound. For this purpose, disc diffusion method was used (Murray et al., 1995). Two Escherichia species (Escherichia coli 0157:H7 ATCC 35150, and E. coli ATCC 25922), three Staphylococcus species (Staphylococcus aureus ATCC BAA 976, S. aureus ATCC 25923, and S. aureus ATCC 1026), Brochothrix thermosphacta ATCC 11509, Bacillus subtilis ATCC 6633, and Enterobacter cloacae ATCC 700323 were used as standard bacterial strains. Nutrient Broth was used to cultivate bacteria $(24 \mathrm{~h})$. They were inoculated uniformly by using sterile cotton swab onto Nutrient Agar to determine the antibacterial activities of the extracts. A $40 \mu \mathrm{l}$ of extracts was applied to a sterile disc ( $40 \mu \mathrm{l} / \mathrm{per}$ disc). The impregnated discs were put on to the plates using sterile forceps properly spaced at equal distance. They were incubated for $24 \mathrm{~h}\left(30^{\circ} \mathrm{C}\right)$. The zone of inhibition was determined in diameter $(\mathrm{mm})$

The chlorophyll $(\mathrm{a}+\mathrm{b})$ in the media was found by observing optical absorption at 646.6 and 663.6 nm (Porra et al., 1989)

\section{HPLC-DAD analysis of the extracts}

HPLC analysis was performed by using an Agilent 1260 Liquid Chromatograph with a DAD to understand the pigment composition. C18 column $(150 \mathrm{~mm} \times 3.9 \mathrm{~mm}, 4 \mu \mathrm{m}$ particle size) in a (zorbax) from ACE was used for the separation. As a mobile phase the mixture of solvent A and solvent B was used. Solvent A (methanol/ammonium acetate $0.1 \mathrm{~N} ; 7: 3$ ) and solvent B (methanol) at $0.9 \mathrm{~mL} / \mathrm{min}$ was applied according to the following step gradient: $25 \% \mathrm{~B}$, changing to $50 \%$ in $1 \mathrm{~min}$, and finally $100 \% \mathrm{~B}$ at minute 20 at $450 \mathrm{~nm}$. The peaks were identified by comparing with the data presented in the literature.

Polar compounds were determined with HPLC (Agilent 1260 Liquid Chromatograph with a DAD). A mixture of solvent $\mathrm{A}\left(\mathrm{H}_{2} \mathrm{O} / \mathrm{CH}_{3} \mathrm{COOH}, 95: 5\right)$ and solvent B (acetonitrile 100\%) was used as mobile phase. Mobile phase was applied with a flow rate as $0.9 \mathrm{~mL} / \mathrm{min}$ at $280 \mathrm{~nm}$. Due to the following step gradient lasting for $30 \mathrm{~min}$, starting from $1 \% \mathrm{~B}$, changing to $2 \% \mathrm{~B}$ at $6 \mathrm{~min}$, increasing to $100 \% \mathrm{~B}$ at $20 \mathrm{~min}$ and holding $100 \% \mathrm{~B}$ constant for the 30 -min run. The peaks were identified by comparing with the data reported in the literature.

\section{Analysis of fatty acids by GC-MS}

To analyse the fatty acid methyl ester analysis for the extracts having the highest bioactive property, extracts were mixed with $0.1 \mathrm{M} \mathrm{KOH}$ in methanol, and for transesterification, hexane was added. A $1 \mu \mathrm{L}$ sample was taken from the upper phase. GCMS-QP2010 Ultra gas-chromatograph (Shimadzu, Japan) was used to analyse the methylated fatty acids. The condition of GCMS-QP2010 Ultra analysis was flame ionization detector (FID-250 ${ }^{\circ} \mathrm{C}$ ); column SP-2560 $(100 \mathrm{~m} \times 0.25 \mathrm{~mm} \times 0.20 \mu \mathrm{m}$, Sigma-Aldrich); carrier gas He. Peaks were identified by the chromatogram of a mixed fatty acid methyl ester standard (37 Comp. FAME Mix $10 \mathrm{mg} / \mathrm{mL}$ in $\mathrm{CH}_{2} \mathrm{Cl}_{2}$; Supelco, USA).

\section{RESULTS AND DISCUSSION}

\section{The microalga having the most effective bioactive compound}

Ten different microalgal strains (Strain A, Strain B, Strain C, Strain D, Strain E, Strain F, Strain G, Strain A1, Strain A2, and Strain A3) were tested in these experiments. The data were summarized in Table 1 . All microalgal isolates had antimicrobial activity to B. subtilis ATCC 6633, B. thermosphacta ATCC 11509 , E. coli 0157:H7 ATCC 35150, S. aureus ATCC BAA 976 and S. aureus ATCC 25923. Among them, extracts of Strain C were not effective to $E$. coli ATCC 25922 and E. cloacae ATCC 700323; extracts by Strain G and Strain A3 had no antimicrobial activity against $S$. aureus ATCC 1026 . According to the results from these experiments, ethanol-extracts of Strain A had the most effective antimicrobial activity against $S$. aureus ATCC 1026 and S. aureus ATCC BAA 976 with an inhibition zone as $14 \mathrm{~mm}$. In addition, Strain D and Strain A2 extracts had effective bioactive properties against E. coli ATCC 25922 with inhibition zones as $12.5 \mathrm{~mm}$. At the end of these trials, further experiments were carried out with the microalga (Strain A) with the most effective antimicrobial activity.

Table 1 Antimicrobial activity [inhibition zone $(\mathrm{mm})$ ] of bioactive compounds obtained from microalgal species $\left(\mathrm{T}: 45^{\circ} \mathrm{C} ; \mathrm{N}\right.$ concentration: $1 \mathrm{~g} / \mathrm{L} ;$ illumination: 2400 lx; incubation period: $14 \mathrm{~d}$ )

\begin{tabular}{|c|c|c|c|c|c|c|c|c|c|c|}
\hline \multirow{2}{*}{ Bacteria } & \multicolumn{10}{|c|}{ Strain } \\
\hline & $\mathbf{A}$ & B & $\mathbf{C}$ & D & $\mathbf{E}$ & $\mathbf{F}$ & $\mathbf{G}$ & A1 & A2 & $\mathbf{A 3}$ \\
\hline B. subtilis ATCC 6633 & $12 \pm 2.0$ & $6.5 \pm 1.5$ & $9 \pm 1.0$ & $10 \pm 0.5$ & $12 \pm 1.0$ & $8 \pm 1.0$ & $7 \pm 2.0$ & $10 \pm 1.0$ & $7 \pm 2.0$ & $9 \pm 1.5$ \\
\hline B. thermosphacta ATCC 11509 & $12 \pm 1.5$ & $12 \pm 1.0$ & $8 \pm 0.5$ & $9 \pm 1.5$ & $11 \pm 0.5$ & $8.5 \pm 1.5$ & $7 \pm 1.5$ & $8 \pm 1.5$ & $6.5 \pm 1.0$ & $8.5 \pm 1.0$ \\
\hline E. coli 0157:H7 ATCC 35150 & $11.5 \pm 1.0$ & $11.5 \pm 1.0$ & $10 \pm 0.5$ & $10 \pm 1.0$ & $12 \pm 1.0$ & $10 \pm 0.5$ & $8 \pm 1.0$ & $6 \pm 2.0$ & $10 \pm 1.0$ & $7 \pm 1.0$ \\
\hline E. coli $A T C C 25922$ & $11 \pm 1.0$ & $7 \pm 1.0$ & - & $12.5 \pm 1.0$ & $10 \pm 1.5$ & $10 \pm 1.5$ & $6 \pm 2.0$ & $8 \pm 1.5$ & $12.5 \pm 0.5$ & $8 \pm 1.5$ \\
\hline E. cloacae ATCC 700323 & $12 \pm 1.0$ & $11 \pm 1.0$ & - & $8 \pm 2.0$ & $7 \pm 0.5$ & $11 \pm 1.5$ & $7 \pm 1.5$ & $10 \pm 1.0$ & $8 \pm 1.0$ & $7 \pm 1.0$ \\
\hline S. aureus ATCC BAA 976 & $14 \pm 1.5$ & $6.5 \pm 1.5$ & $7 \pm 1.5$ & $10 \pm 1.5$ & $9 \pm 2.0$ & $10 \pm 0.5$ & $6 \pm 1.5$ & $7 \pm 1.5$ & $8 \pm 1.5$ & $9 \pm 0.5$ \\
\hline S. aureus ATCC 25923 & $12 \pm 0.5$ & $6.5 \pm 1.5$ & $9 \pm 0.5$ & $8 \pm 2.0$ & $9 \pm 2.0$ & $11 \pm 1.5$ & $6 \pm 2.0$ & $9 \pm 1.5$ & $12 \pm 1.0$ & $8 \pm 1.0$ \\
\hline S. aureus ATCC 1026 & $14 \pm 1.5$ & $12 \pm 0.5$ & $8 \pm 2.0$ & $11 \pm 1.0$ & $10 \pm 1.0$ & $8.5 \pm 1.0$ & - & $9 \pm 0.5$ & $7 \pm 2.0$ & - \\
\hline
\end{tabular}

\section{Identification of the Selected Microalga}

Strain A was identified by amplification and sequencing of its 18S rDNA gene. BLAST search was performed to find the phylogenetic analysis of the nearly complete sequence data. The microalga had a $>99 \%$ similarity to Chlorella vulgaris according to the alignment and further analysis in ARB database. The microalga was submitted to NCBI Gen-Bank with accession number as MN 114114

Effect of different nitrogen concentrations on bioactive compound effectiveness under $30^{\circ} \mathrm{C}$ and $45^{\circ} \mathrm{C}$

Under $30^{\circ} \mathrm{C}$, the most effective bioactive compound was obtained from extracts by microalga cultivated in media with $0.5 \mathrm{~g} / \mathrm{L}$ nitrogen to $S$. aureus ATCC 1026 and S. aureus ATCC 25923 with inhibition zones as $11 \mathrm{~mm}$ and $10.5 \mathrm{~mm}$, respectively (Figure 1a). On the other hand, at $45^{\circ} \mathrm{C}$, effectiveness of bioactive compounds was higher than it was at $30^{\circ} \mathrm{C}$ against only one bacterium as $S$. aureus ATCC BAA 976 (inhibition zone: $12 \mathrm{~mm}$ ) produced by $C$. vulgaris grown in media with the same nitrogen concentration. Under $45^{\circ} \mathrm{C}$, antimicrobial activity was found same against S. aureus ATCC 1026 and less than it was at $30{ }^{\circ} \mathrm{C}$ against other bacteria tested.

The extracts obtained from the biomass when the microalgae were grown in medium with $1 \mathrm{~g} / \mathrm{l}$ of nitrogen at $30^{\circ} \mathrm{C}$, showed the maximum antimicrobial activity to $S$. aureus ATCC BAA 976 and S. aureus ATCC 1026 with $14 \mathrm{~mm}$ inhibition zones (Figure 1b). Extracts produced by C. vulgaris grown in the same media at $45^{\circ} \mathrm{C}$, had lower antimicrobial activity than it was $30^{\circ} \mathrm{C}$. Extracts from microalgal biomass obtained under $45^{\circ} \mathrm{C}$, had the most effective activity to $E$. coli 0157:H7 ATCC 35150 (inhibition zone: $11.5 \mathrm{~mm}$ ) 
When C. vulgaris was cultivated in media with $1.5 \mathrm{~g} / \mathrm{L}$ at $30^{\circ} \mathrm{C}$ and $45^{\circ} \mathrm{C}$, antimicrobial activity of extracts was shown in Figure 1c. The highest activity (inhibition zone: $11 \mathrm{~mm}$ ) was observed against $S$. aureus ATCC 1026 with $30^{\circ} \mathrm{C}$ extracts, while it was $12 \mathrm{~mm}$ with $45^{\circ} \mathrm{C}$-extracts towards to the same bacterium. In these experiments, it was observed that extracts obtained in media at $30^{\circ} \mathrm{C}$ had lower bioactive property than it was with $45{ }^{\circ} \mathrm{C}$-extracts. On the other hand, antimicrobial activity had its highest value in samples obtained in media with $1 \mathrm{~g} / \mathrm{L}$ nitrogen at $30^{\circ} \mathrm{C}$.

When antimicrobial activities of extracts obtained from algal biomass grown at 30 ${ }^{\circ} \mathrm{C}$ and $45^{\circ} \mathrm{C}$ were compared, it was concluded that $30{ }^{\circ} \mathrm{C}$-extracts had higher bioactive character. Further raising the temperature to $45^{\circ} \mathrm{C}$ made a decrease of microalgal growth, and later the microalgal cells died. This result was celarly followed as the color of the cells changed from green to brown, and as a result the chlorophyll content decreased, as well. Chlorophyll of the microalga were 2.2 $\mu \mathrm{g} / \mathrm{ml}, 3.3 \mu \mathrm{g} / \mathrm{ml}, 1.9 \mu \mathrm{g} / \mathrm{ml}$ when $C$. vulgaris was cultivated in media under 0.5 $\mathrm{g} / \mathrm{L}, 1.0 \mathrm{~g} / \mathrm{L}$, and $1.5 \mathrm{~g} / \mathrm{L}$ nitrogen concentrations at $30^{\circ} \mathrm{C}$, respectively. On the other hand, when $C$. vulgaris was cultivated at $45^{\circ} \mathrm{C}$ in BG11 including $0.5 \mathrm{~g} / \mathrm{L}$ nitrogen, chlorophyll content was $0.6 \mu \mathrm{g} / \mathrm{ml}$; in media having $1.0 \mathrm{~g} / \mathrm{L}$ nitrogen, it was $0.7 \mu \mathrm{g} / \mathrm{ml}$, and under $1.5 \mathrm{~g} / \mathrm{L}$ nitrogen conditions chlorophyll amount was 0.4 $\mu \mathrm{g} / \mathrm{ml}$.

In addition to this, bioactive compounds affected S. aureus ATCC BAA 976 and S. aureus ATCC 1026 at most. According to these results, further experiments were done with using S. aureus ATCC BAA 976 and S. aureus ATCC 1026 bacteria. Different environmental properties such as temperature and the nitrogen content in the media are factors that affect microalgal growth and affect the effectiveness of bioactive substances obtained from microalgae. For this purpose, to understand that affect, the concentration of nitrate in media was diminished to half and increased to half of the standard media, while the illumination was kept the same during the trials.

At the end of these trials, the effect of nitrogen concentration and the temperature on antimicrobial activity were evaluated together, increasing the amount of nitrogen had more effect than the increase in temperature on the antimicrobial effect. In addition, the highest bioactive character was found in the biomass obtained from the microalgae grown at $30{ }^{\circ} \mathrm{C}$ and $1 \mathrm{~g} / \mathrm{L}$ nitrogen containing medium. The variation of efficiency of bioactive character with these parameters is due to the fatty acids, polar compounds and pigments that are produced in microalgae under different ambient conditions. Converti et al. (2009) also showed that growth of $C$. vulgaris decreased as the temperature increased. In the same study, no change in the fatty acid composition was observed by changing the nitrogen content from $0.375 \mathrm{~g} / \mathrm{L}$ to $1.5 \mathrm{~g} / \mathrm{L}$. In the current study, with an increase in temperature, growth of the $C$. vulgaris decreased. On the other hand, the extracts prepared from biomasses obtained by increasing the nitrogen concentration from $0.5 \mathrm{~g} / \mathrm{L}$ to $1.0 \mathrm{~g} / \mathrm{L}$ were found to have more effective bioactive substances. This case may be due to fatty acids having more antimicrobial activity in that media.
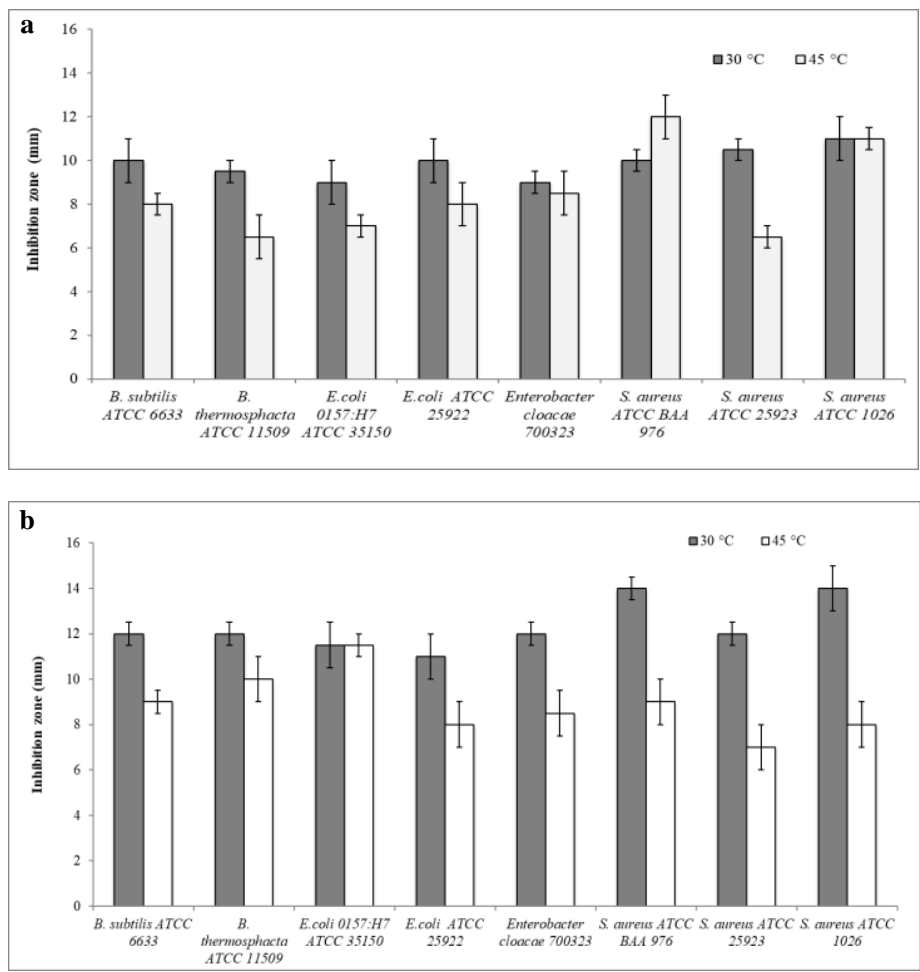

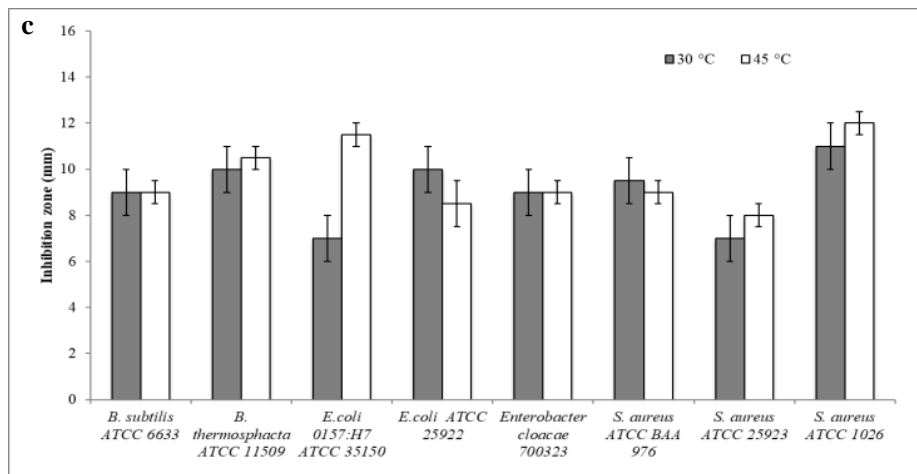

Figure 1 Antimicrobial activities [inhibition zone $(\mathrm{mm})$ ] of bioactive compounds by $C$. vulgaris (a) $0.5 \mathrm{~g} / \mathrm{L}$ nitrogen (b) $1.0 \mathrm{~g} / \mathrm{L}$ nitrogen (c) $1.5 \mathrm{~g} / \mathrm{L}$ nitrogen (T: 30 ${ }^{\circ} \mathrm{C}$ and $45^{\circ} \mathrm{C}$; illumination: $2400 \mathrm{~lx}$; incubation period: $14 \mathrm{~d}$ )

In addition to this subject, $C$. vulgaris produced more effective bioactive compounds when grown in media with $1.5 \mathrm{~g} / \mathrm{L}$ nitrogen at $45{ }^{\circ} \mathrm{C}$ then in media with same nitrogen but at $30^{\circ} \mathrm{C}$

In the current work, with an increase in temperature growth of the microalga decreased. Converti et al. (2009) also reported that $C$. vulgaris was adversely affected by the increase in temperature above $30^{\circ} \mathrm{C}$ and growth was not observed at $38^{\circ} \mathrm{C}$. In the same study, with the reduction of nitrogen, the composition of fatty acids was obtained in a similar amount and was not affected by this parameter only the temperature affected the content of fatty acid, which was only for one fatty acid as linolenic acid. Results showed that antimicrobial activity of the tested alga can only be induced by high nitrogen concentrations and temperature.

\section{Effect of different solvents}

In Figure 2 antimicrobial effectiveness of bioactive compounds obtained with ethanol, methanol, chloroform, Tris-HCI, hexane, and water were shown. These extracts were tested against S. aureus ATCC BAA 976 and S. aureus ATCC 1026 bacteria which microalgal extracts had the highest antimicrobial activity under tested conditions.

In these trials, extracts obtained with ethanol and chloroform showed the highest antimicrobial activity against the tested bacteria. Inhibition zones with chloroformextracts were $17 \mathrm{~mm}$ to $S$. aureus ATCC BAA 976 and $16 \mathrm{~mm}$ to $S$. aureus ATCC 1026. On the other hand, bioactive compounds prepared with ethanol solvent, had $14 \mathrm{~mm}$ inhibition zones to the tested bacteria.

Methanol and Tris-HCI extracts had similar antimicrobial character, while hexane and water-extracts had no bioactive character to the tested bacteria.

Pigment content of the microalgae can be affected from used solvents. Previous studies on this subject vary considerably. Kitada et al. (2009) found that ethano was better than acetone in the study they investigated the isolation of $C$. vulgaris microalgae pigments with different separation techniques. Syed et al. (2015) also supported that ethanol was a better solvent then acetone. On the other hand, Plaza et al. (2012) used different solvents like ethanol, hexane, and acetone; they found that acetone was to be the best solvent to get more Chlorella carotenoids. Ibrahim et al. (2015) used ethanol as an extraction solvent; they found that C. vulgaris extracts formed $11 \mathrm{~mm}$ inhibition zone against $S$. aureus. However, in the present study, chloroform was the most effective organic solvent to have more efficient extracts from C. vulgaris; and chloroform extracts of $C$. vulgaris had $17 \mathrm{~mm}$ inhibition zone against $S$. aureus ATCC BAA 976.

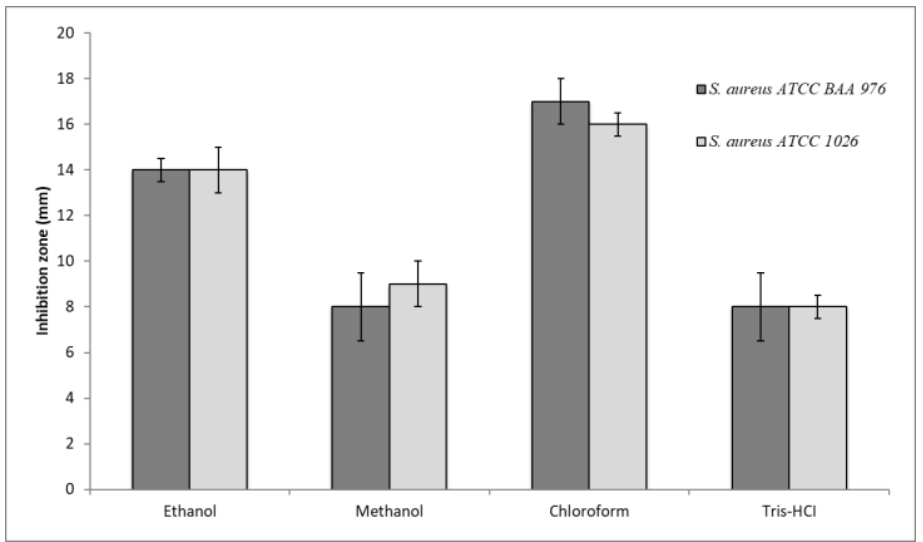

Figure 2 Antimicrobial activity of bioactive compounds obtained with differen solvents to S. aureus ATCC BAA 976 and S. aureus ATCC 1026 (T: $30^{\circ} \mathrm{C}$; N concentration: $1 \mathrm{~g} / \mathrm{L}$; illumination: $2400 \mathrm{~lx}$; incubation period: $14 \mathrm{~d}$ ) 


\section{HPLC and GC analysis}

\section{Analysis of fatty acids by GC-MS}

Chloroform-extracts of C.vulgaris having the maximum bioactive character were analysed to find the fatty acid profile. In Table 2 fatty acid definition, the peak area contribution, and the concentration of fatty acids were shown. Stearic (26.9\%), caprylic $(14.9 \%)$, palmitic $(14.5 \%)$ and lauric acids $(10.9 \%)$ were found to be the major fatty acids due to the chromatographic area as nearly $70 \%$ in total. Similar results were found in previous studies. Converti et al. (2009) showed that $C$. vulgaris produced more saturated fatty acids like palmitic acid (C 16:0) when temperature raised above $30{ }^{\circ} \mathrm{C}$. Researchers also concluded that unsaturated fatty acids could only be produced when temperature was lower than $20^{\circ} \mathrm{C}$ (Ahn et al., 2016). The results of our study are also supported by these previous works.

Table 2 Fatty acid identification in chloroform-extracts of $C$. vulgaris by GC-MS analysis

\begin{tabular}{lccc} 
ID & $\begin{array}{c}\text { Retention } \\
\text { time (min) }\end{array}$ & Fatty acids & $\%$ \\
\hline $\mathbf{1}$ & 13.39 & Caprylic acid $(\mathrm{C} 8: 0)$ & 14.90 \\
\hline $\mathbf{2}$ & 16.99 & Lauric acid $(\mathrm{C} 12: 0)$ & 10.9 \\
\hline $\mathbf{3}$ & 26.60 & Palmitic acid $(\mathrm{C} 16: 0)$ & 14.5 \\
\hline $\mathbf{4}$ & 27.46 & Palmiteloic acid $(\mathrm{C} 16: 1)$ & 4.07 \\
\hline $\mathbf{5}$ & 29.59 & Cis-10-Heptadecanoic acid $(\mathrm{C} 17: 1)$ & 4.03 \\
\hline $\mathbf{6}$ & 30.34 & Stearic acid $(\mathrm{C} 18: 0)$ & 26.9 \\
\hline $\mathbf{7}$ & 30.60 & Elaidic acid $(\mathrm{C} 18: 1 \mathrm{n} 9 \mathrm{t})$ & 1.69 \\
\hline $\mathbf{8}$ & 31.52 & Oleic acid $(\mathrm{C} 18: 1 \mathrm{n} 9 \mathrm{c})$ & 5.59 \\
\hline $\mathbf{9}$ & 32.30 & Linolelaidic acid $(\mathrm{C} 18: 2 \mathrm{n} 6 \mathrm{t})$ & 1.68 \\
\hline $\mathbf{1 0}$ & 33.30 & Linoleic acid $(\mathrm{C} 18: 2 \mathrm{n} 6 \mathrm{c})$ & 3.3 \\
\hline $\mathbf{1 1}$ & 35.34 & Heneicosanoic acid $(\mathrm{C} 21: 0)$ & 3.7 \\
\hline $\mathbf{1 2}$ & 39.30 & Cis-13,16 docosadienoic acid $(\mathrm{C} 22: 2)$ & 1.7 \\
\hline $\mathbf{1 3}$ & 39.9 & lignoceric acid $(\mathrm{C} 24: 0)$ & 3.3 \\
\hline $\mathbf{1 4}$ & 44.27 & Cis-4,7,10,13,16,19 docosahexaenoic acid & 3.7 \\
\hline
\end{tabular}

\section{HPLC-DAD analysis of the extracts}

In C. vulgaris chloroform-extracts, it was determined that main component of pigments was 19'butanoyloxyfucoxanthin according to the highest chromatographic area. It was followed by $\beta$-carotene, and lutein (Table 3 ).

Microalgae had pigments like carotenoids (carotenes) and xanthophyll (lutein, astaxanthin, fucoxanthin etc.) which are bioactive compounds having antimicrobial, antioxidant, anti-inflammatory properties (Koller et al., 2014; Encarnação et al., 2015; Falaise et al., 2016). In the current study, high amount of fucoxanthin following by $\beta$-carotene, and lutein were found as main carotenoid having bioactive property.

Previous studies showed that $C$. vulgaris contained pigments such as xanthophyll, lutein, a-carotene and b-carotene (Plaza et al., 2012; da Silva vaz et al., 2016). Of these, fucoxanthin having the highest chromatographic area in the current study was previously reported that it had antimicrobial activity against Listeria monocytogenes (Rajauira and Abu-Ghannam, 2013). Furthermore, fucoxanthin is thought to be a good candidate to develop new drugs (Peng et al., 2011). Antimicrobial, antioxidant, anti-inflammatory characters of $\beta$-carotene and lutein were also studied by other researchers (Plaza et al., 2012; de Morais et al., 2015) Table 4 summarized analyses of polar compounds in $C$. vulgaris chloroformextracts. Rodriguez-Meizoso et al., (2010) mentioned that HPLC analysis of polar compounds $(280 \mathrm{~nm})$ in microalgal extracts might be connected to phenolic compounds having bioactive character. Chromatogram of polar compounds showed that 12 peaks were obtained; of these, 7., 8., and 9. peaks (Retention time: $21.73,22.07,22.57$, respectively) had higher intensity from other peaks. Zhang et al. (2013) demonstrated that these compounds may be related to caffeic acid according to their retention time. It was previously mentioned that $C$. vulgaris contained phenolic compounds; these compounds included phenolic acids such as caffeic acid. Caffeic acid was previously studied for its antimicrobial activity to $E$. coli (Meyuhas et al., 2015 Matejczyk et al., 2018). To the best our knowledge, caffeic acid having antimicrobial effect was firstly shown in thermotolerant $C$. vulgaris in the current study.

Table 3 Pigment composition in C. vulgaris extracts obtained with chloroform, $450 \mathrm{~nm}$.

\begin{tabular}{|c|c|c|c|c|}
\hline ID & $\begin{array}{l}\text { Retention } \\
\text { time (min) }\end{array}$ & Compound & Area & Reference \\
\hline 1 & 10.41 & Zeaxanthin (RT:10.39; $448 \mathrm{~nm})$ & 109.88 & (Plaza et al., 2010) \\
\hline 2 & 10.75 & Luteoxanthin (RT: 9.64; $446 \mathrm{~nm}$ ) & 155.77 & (Deli et al., 2014) \\
\hline 4 & 11.19 & Chlorophyll c2 (RT: $11.01 ; 452 \mathrm{~nm})$ & 9.76 & (Rodriguez et al., 2002) \\
\hline 5 & 11.46 & Chlorophyll c1 (RT: $11.72 ; 448 \mathrm{~nm})$ & 7.25 & (Rodriguez et al., 2002) \\
\hline 8 & 20.18 & Alloxanthin (RT:20.8; $454 \mathrm{~nm})$ & 472.87 & (Louda et al., 2008) \\
\hline 9 & 21.43 & $\beta$-carotene (RT:22.43; $452 \mathrm{~nm})$ & 536.93 & (Plaza et al., 2010) \\
\hline 10 & 24.07 & Lutein (RT:24.3; $445 \mathrm{~nm})$ & 383.61 & (Serive et al., 2017) \\
\hline 11 & 25.00 & Crocoxanthin (RT: $24.80 ; 446 \mathrm{~nm})$ & 188.41 & (Mendes et al., 2007) \\
\hline 12 & 31.54 & $\alpha$-carotene (RT: $31.93 ; 444 \mathrm{~nm})$ & 454.02 & (Deli et al., 2014) \\
\hline 13 & 34.56 & $\beta-\varepsilon$ carotene (RT: $35.39 ; 452 \mathrm{~nm})$ & 323.18 & (Rodriguez et al., 2002) \\
\hline
\end{tabular}

Table 4 Polar compound composition in C. vulgaris extracts obtained with chloroform

\begin{tabular}{lcc}
\hline ID & Retention time (min) & Area \\
\hline $\mathbf{4}$ & 19.68 & 3904.9 \\
$\mathbf{5}$ & 19.84 & 3896.5 \\
$\mathbf{6}$ & 21.29 & 2609.1 \\
$\mathbf{7}$ & 21.73 & 6537.2 \\
$\mathbf{8}$ & 22.07 & 4091.2 \\
$\mathbf{9}$ & 22.57 & 5016.3 \\
$\mathbf{1 0}$ & 22.83 & 2890.3 \\
$\mathbf{1 1}$ & 23.72 & 77.7 \\
$\mathbf{1 2}$ & 24.34 & 59.5 \\
$\mathbf{1 3}$ & 24.70 & 141.9 \\
$\mathbf{1 4}$ & 25.81 & 1435.4 \\
$\mathbf{1 5}$ & 28.72 & 2432.6 \\
\hline
\end{tabular}

\section{CONCLUSION}

Antimicrobial activities of bioactive compounds in $C$. vulgaris were studied in the current study. When bioactive properties examined it was concluded that antimicrobial activity of the tested alga can only be induced by high nitrogen concentrations and temperature. The highest antimicrobial activity was found to $S$ aureus ATCC BAA 976 and S. aureus ATCC 1026. In addition to this, antimicrobial activity increased with using different solvents rather than ethanol. Chloroform-extracts had higher antimicrobial activity than extracts obtained with other solvents tested. Of the fatty acids identified, stearic acid, fucoxanthin from pigments and caffeic acid as a simple phenol from polar compounds were found with their highest amount in chloroform-extracts of the $C$. vulgaris. It can be stated that fucoxanthin and caffeic acid were responsible for more effective antimicrobial activity at conditions like $45{ }^{\circ} \mathrm{C}$ and media with $1.5 \mathrm{~g} / \mathrm{L}$ nitrogen. Thus, thermotolerant $C$. vulgaris is an advantageous biomaterial to be used in several biotechnological applications due to its unique properties.

\section{REFERENCES}

Ahn, H. M., Kim, S-H., Hyun, S-H., Lim, S. R., Kim, H-Y., Oh, J., Lee, K-M., Hong, S-J., Cho, B-K., Lee, H., Lee, C-G. \& Choi, H-K. (2016). Effects of the timing of a culture temperature reduction on the comprehensive metabolite profiles of Chlorella vulgaris. Journal of Applied Phycology, 28, 2641-2650. http://dx.doi.org/10.1007/s10811-016-0817-4

Alzahrani, M. A. J., Perera, C. O., Sabaragamuwa, Y. \& Hemar, Y. (2019) Assessment of Bioactive Potential of Aqueous Protein Extracts from Diatoms Nitzschia laevis, Spirulina platensis, and Chlorella vulgaris. Journal of Aquatic Food Product Technology, 28(2), 177-193. http://dx.doi.org/10.1080/10498850.2019.1571551

Chaidir, Z., Syafrizayanti Hillman, P. F. \& Zainul, R. (2016). Isolation and identification of freshwater microalgae potentially as antibacterial from Talago 
Biru, Koto Baru, West Sumatera. Der Pharmacia Lettre, 8(20), 157-165. http://dx.doi.org/10.17605/OSF.IO/5MR9Y

Converti, A., Casazza, A. A.

Ortiz, E. Y., Perego, P. \& Del Borghi, M. (2009). Effect of temperature and nitrogen concentration on the growth and lipid content of Nannochloropsis oculata and Chlorella vulgaris for biodiesel production. Chemical Engineering and Processing, 48, 1146-1151. http://dx.doi.org/10.1016/j.cep.2009.03.006

Deli, J., Gonda, S., Nagy, L. Z. S., Szabó, I., Gulyás-Fekete, G., Agócs, A., Marton, K. \& Vasas, G. (2014). Carotenoid composition of three bloom-forming algae species. Food Research International, 65, 215-223. http://dx.doi.org/10.1016/j.foodres.2014.05.02

Encarnação, T., Pais, A. A. C. C., Campos, M. G. \& Burrows, H. D. (2015) Cyanobacteria and microalgae: a renewable source of bioactive compounds and other chemicals. Science Progress, 98(2), 145-168. http://dx.doi.org/10.3184/003685015X14298590596266 Falaise,

C., François, C., Travers, M-A., Morga, B., Haure, J., Tremblay, R., Turcotte, F., Pasetto, P., Gastineau, R., Hardivillier, Y., Leignel,

V. \& Mouget, J-L. (2016). Antimicrobial Compounds from Eukaryotic Microalgae against Human Pathogens and Diseases in Aquaculture. Marine Drugs, 14(9), 1 27. http://dx.doi.org/10.3390/md14090159

Gamal, A. A. (2010). Biological importance of marine algae. Saudi Pharmeceutical Journal, 18, 1-25. http://dx.doi.org/10.1016/j.jsps.2009.12.001 Ibrahim, K., Ramli, R., Rashid, A. H. A. \& Yusof, Y. A. M. (2015). Antimicrobial Property of Water and Ethanol Extract Chlorella vulgaris: A Value-Added Advantage for a New Wound Dressing Material, Internal Medical Journal, 22(5), 399-340.

Jayshree,

A., Jayashree, S. \& Thangaraju, N. (2016). Chlorella vulgaris and Chlamydomonas reinhardtii: Effective Antioxidant, Antibacterial and Anticance Mediators. Indian Journal of Pharmeceutical Sciences, 78(5), 575-581. http://dx.doi.org/10.4172/pharmaceutical-sciences.1000155.

Kitada, K., Machmudah, S., Sasaki, M., Goto, M., Nakashima, Y., Kumamoto, S. \& Hasegawa, T. (2009). Supercritical $\mathrm{CO}_{2}$ extraction of pigment components with pharmaceutical importance from Chlorella vulgaris. Journal of Chemical Technology and Biotechnology, 84, 657-661. http://dx.doi.org/10.1002/jctb.2096 Koller, M., Muhr, A. \& Gerhart Braunegg, G. (2014). Microalgae as versatile cellular factories for valued products. Algal Research, 6, 52-63. http://dx.doi.org/10.1016/j.algal.2014.09.002

Louda, J. W., Neto, R. R., Magalhaes, A. R. M. \& Schneider, V. F. (2008). Pigment alterations in the brown mussel Perna perna. Comparative Biochemistry and Physiology Part B, 150, 385-394. http://dx.doi.org/10.1016/j.cbpb.2008.04.008

Maadane, A., Merghoub, N., El Mernissi, N., Ainane, T., Amzazi, S., Wahby, I. \& Bakri, Y. (2017). Antimicrobial Activity of Marine Microalgae Isolated From Moroccan Coastlines. Journal of Microbiology, Biotechnology and Food Sciences, 6(6), 1257-1260. $\quad$ http://dx.doi.org/10.15414/jmbfs.2017.6.6.1257-1260 Matejczyk, M., Swislocka, R., Kalinowska, M., Swiderski, G., LewandowskI, W. \& Jablonska-Trypuc, A. 2017. Monitoring Of Synergistic Enhancement Of Caffeic Acid On Escherichia coli K-12 Reca::Gfp Strain Treated With Dacarbazine. Acto Poloniae Pharmeceutica-Drug Research, 74(39), 809-816.

de Morais, M.G., Vaz, Bda. S., de Morais, E.G. \& Costa, J.A. (2015). Biologically Active Metabolites Synthesized by Microalgae. BioMed Research International Article ID 835761: 1-15. http://dx.doi.org/10.1155/2015/835761

Mendes, C. R., Cartaxana, P. \& Brotas, V. (2007). HPLC determination of phytoplankton and microphytobenthos pigments: comparing resolution and sensitivity of $\mathrm{a}_{18}$ and $\mathrm{C}_{8}$ method. Limnology and Oceanography.: Methods, 5 , 363-370.

http://dx.doi.org/10.4319/lom.2007.5.363

Meyuhas, S., Assali, M., Huleihil, M. \& Huleihel, M. (2015). Antimicrobia activities of caffeic acid phenethyl ester. Journal of Molecular Biochemistry, 4, 21 31.

Murray, P. R., Baron, E. J., Pfalle, M. A., Tenover, F. C. \& Yolke, R. H. (1995) Manual of 490 clinical microbiology (6 ${ }^{\text {th }}$ Ed.) Washington, DC, United States ASM Press., $1482 \mathrm{pp}$.

Peng, J., Yuan, J-P., Wu, C-F. \& Wang, J-H. (2011). Fucoxanthin, a Marine Carotenoid Present in Brown Seaweeds and Diatoms: Metabolism and Bioactivities Relevant to Human Health. Marine Drugs, 9, 1806-1828. http://dx.doi.org/10.3390/md9101806

Plaza, M., Santoyo, S., Jaime, L., Reina, GG-B., Herrero, M., Seňoráns, F. J. \& Ibáez, E. (2010). Screening for bioactive compounds from algae. Journal of Pharmeceutical and Biomedical Analysis, 51, 450-455. http://dx.doi.org/10.1016/j.jpba.2009.03.016 Plaza, M. Santoyo, S., Jaime, L., Avalo, B., Cifuentes, A., Reglero, G., Reina, G.G-B., Señoráns, F. J. \& Ibáñez, E. (2012). Comprehensive characterization of the functional activities of pressurized liquid and ultrasound-assisted extracts from Chlorella vulgaris. LWT-Food Science and Technology, 46, 245-253. http://dx.doi.org/10.1016/j.lwt.2011.09.024

Porra, R. J., Thompson, W. A. \& Kreidemann, P. E. (1989). Determination of accurate extinction coefficients and simultaneous equations for assaying chlorophylls $\mathrm{a}$ and $\mathrm{b}$ extracted with four different solvents: verification of the concentration of chlorophyll standards by atomic absorption spectroscopy, Biochimica et Biophysica Acta. (BBA)-Bioenergetics, 975, 384-394 http://dx.doi.org/10.1016/S0005-2728(89)80347-0
Pradhan, J., Das, B. K., Sahu, S., Marhual, N. P., Swain, A. K., Mishra, B. K. \& Eknath, A. E. (2012). Traditional antibacterial activity of freshwater microalga Spirulina platensis to aquatic pathogens. Aquatic Research, 43, 1287-1295. http://dx.doi.org/10.1111/j.1365-2109.2011.02932.x

Priya, S. (2012). Analysis of value-added biochemical compounds and antimicrobial activity of green algae Chlorella vulgaris. Journal of Chemical and Pharmeceutical Research, 4, 2577-2579.

Rajauira, G. \& Abu-Ghannam, N. (2013). Isolation and Partial Characterization of Bioactive Fucoxanthin from Himanthalia elongata Brown Seaweed: A TLC-Based Approach. International Journal of Analiytical Chemistry, ID 802573, 1-6. http://dx.doi.org/10.1155/2013/802573.

Rao, A. R., Reddy, A. H. \& Aradhya, S. M. (2010). Antibacterial properties of Spirulina platensis, Haematococcus pluvialis, Botryococcus braunii micro alga extracts. Current Trends in Biotechnoogy and. Pharmacy,4(3), 809-819. Rippka, R. (1988). Recognition and identification of cyanobacteria, Methods in Enzymology, 167(28-67). http://dx.doi.org/10.1016/0076-6879(88)67005-4

Rodriguez, F., Varela, M. \& Zapata, M. (2002). Phytoplankton assemblages in the Gerlache and Bransfield Straits (Antarctic Peninsula) determined by light microscopy and CHEMTAX analysis of HPLC pigment data. Deep-Sea Research Part II: topical Studies in Oceanography, 49, 723-747. http://dx.doi.org/10.1016/S0967-0645(01)00121-7

Rodríguez-Meizoso, I., Jaime, L., Santoyo, S., Senoráns, F. J., Cifuentes, A. \& Ibánez, E. (2010). Subcritical water extraction and characterization of bioactive compounds from Haematococcus pluvialis microalga. Journal of Pharmeceutical and Biomedical Analysis $\quad 51,456-463$. http://dx.doi.org/10.1016/j.jpba.2009.03.014

Serive, B., Nicolau, E., Berard, J-B., Kaas, R., Pasquet, V., Picot, L., \& Cadoret, J-P. (2017). Community analysis of pigment patterns from 37 microalgae strains reveals new carotenoids and porphyrins characteristic of distinct strains and taxonomic groups. PLoS ONE, 12(2), e0171872. http://dx.doi.org/10.1371/ journal.pone.0171872

Syed, S., Arasu, A. \& Ponnuswamy, I. (2015). The Uses of Chlorella Vulgaris as Antimicrobial Agent and as a Diet: the Presence of Bio-active Compounds which caters the Vitamins, Minerals in General. International Journal of Bio-Science and Bio-Technology, 7(1) 185-190. http://dx.doi.org/10.14257/ijbsbt.2015.7.1.19 da Silva Vaz, B., Moreira, J. B., de Morais, M. G. \& Costa, J. A. V. (2016) Microalgae as a new source of bioactive compounds in food supplements. Current Opinion in Food Science, 7, 73-77. http//dx.doi.org/10.1016/j.cofs.2015.12.006 Zhang, A., Wan, L., Wu, C., Fang, Y., Han, G., Li, H., Zhang, Z. \& Wang, H. (2013). Simultaneous Determination of 14 Phenolic Compounds in Grape Canes by HPLC-DAD-UV Using Wavelength Switching Detection. Molecules, 18 14241-14257. http://dx.doi.org/10.3390/molecules181114241 